\title{
El 'passage' del campo a la ciudad. Andanzas y mudanzas de una antropóloga
}

The passage from country to city. The comings and goings of a woman anthropologist

\author{
María Cátedra \\ Departamento de Antropología Social. Universidad Complutense de Madrid \\ mcatedra@cps.ucm.es
}

\author{
30 ANIVERSARIO DE LA GAZETA DE ANTROPOLOGÍA \\ NÚMERO COORDINADO POR FRANCISCO CHECA OLMOS Y CELESTE JIMÉNEZ DE MADARIAGA
}

\begin{abstract}
RESUMEN
Este ensayo trata de exponer la trayectoria formativa y profesional de una antropóloga en el contexto de la situación de la antropología española a partir de su profesionalización. A lo largo del texto se reflexiona sobre el paso de la experiencia individual al escrutinio de las imágenes del trabajo antropológico en la sociedad. Se trata de un intento de introspección de aspectos de la práctica etnográfica encuadrado dentro de la etnografía experimental que agitó la disciplina en el último cuarto del pasado siglo.
\end{abstract}

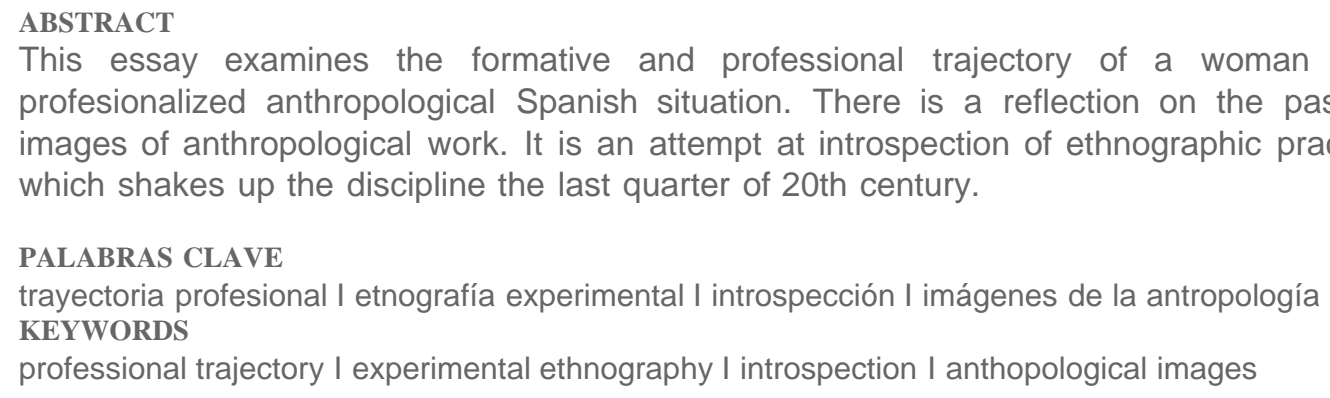
which shakes up the discipline the last quarter of 20th century. profesionalized anthropological Spanish situation. There is a reflection on the passage from individual experience to social images of anthropological work. It is an attempt at introspection of ethnographic practice within the experimental ethnography

\begin{abstract}
“¿Y por qué no haces un trabajo de campo?" La cuestión me la planteó un colega al termino de un más o menos etílico repaso de la situación de la Antropología, la docencia universitaria y la vida académica general. El repaso no había resultado muy favorable. Habíamos hecho inventario y encontrado la alacena vacía.(...) No me fue fácil decidir si hacer trabajo de campo era una de esas tareas desagradables, como el servicio militar, que había que sufrir en silencio (...) Las opiniones de mis colegas no me fueron de mucha ayuda. La mayoría habían tenido tiempo suficiente para envolver sus experiencias en un resplandor rosado de aventura romántica (...) Uno sospechaba que en realidad todo era como esos alegres recuerdos de guerra que, contra toda información objetiva, le hacen a uno lamentar no haber estado vivo en aquella época. - La monografía acabada guarda relación con los "sangrantes pedazos" de la cruda realidad en que se basa" (Nigel Barley).
\end{abstract}

En este ensayo voy a tratar sobre mi propia experiencia de trabajo de campo (1). Me resulta un tanto difícil esta tarea por dos motivos. Uno porque no estamos los antropólogos españoles acostumbrados a ello, fuera del obligado y vergonzoso "auto-bombo" del ritual opositor -un ritual ya fallecido que algunos tuvimos que realizar-. La segunda porque soy consciente que el auto-análisis es bastante dudoso, problemático y nada fácil; al menor descuido se puede convertir en un puro y simple ejercicio narcisístico, 
una petulante laudatio de uno mismo. Por ello intentaré ser lo más concisa y objetiva que mi "poca distancia" de mi misma me lo permita al exponer mi trayectoria formativa y profesional. Voy en primer lugar a tratar de contextualizar mi exposición por lo que me referiré, desde mi perspectiva, a la situación de la Antropología en este país en este ya amplio periodo desde que empecé a practicar la etnografía. En la segunda parte me referiré brevemente a la etnografía experimental donde se encuadra esta reflexión sobre el trabajo de campo. Y espero, sin mucha esperanza, no provocar su aburrimiento porque parece ser que "El hecho de haber realizado trabajo de campo es como una licencia para ponerse pesado" en negro humor de Nigel Barley (2).

\section{- I -}

En torno al mítico 1968 me topé por primera vez con la Antropología (3). Hasta entonces todas mis ideas sobre esta disciplina estaban mezcladas en una nebulosa de cráneos, artefactos y excavaciones. A ello contribuyó la tradición americana de Antropología general, que orientaba básicamente la especialidad que estudiaba, pero hubo una asignatura que marcó muy significativamente mi trayectoria posterior Antropología Social y Aplicada- que, por cierto, no era nada aplicada, me proporcionó la oportunidad no solo de asomarme a esta disciplina sino de mis primeras prácticas de campo: visitas de un par de días a fiestas rurales. Fue suficiente; no dudé un instante, y acepté inmediatamente cuando uno de mis profesores preguntó en clase si alguien quería hacer trabajo de campo; había decidido dedicarme a esta disciplina que más bien provocaba bastante perplejidad en la sociedad de aquella época (4), así como cierta comprensible preocupación de mi familia por mi futuro. Desde entonces quedé fascinada por la antropología y aún hoy todavía lo estoy, a pesar de los pesares -y hay unos cuantos pesares-.

¿Qué es lo que mueve a una persona a hacer trabajo de campo? Hay razones personales, coyunturales, pragmáticas y humanas, además de las intelectuales. La fundamental suele ser menos altruista de lo que reconocemos: el realizar una Tesis Doctoral y con ello conseguir un posible empleo (o no perderlo), pero además hay muchas otras, como la necesidad de cambio y aventura, el tratar de escapar de una crisis, la comprensión de uno mismo, ganar fama y notoriedad, saciar una curiosidad malsana, etc. No me parecen nimios ni irrelevantes porque creo que cuando uno conoce sus propios motivos para pedir información podrá entender mejor los ajenos para darla. En mi caso, entre otras razones, la investigación significaba la posibilidad de convertirme en la mujer profesional e independiente que quería llegar a ser, aunque no estaba nada segura de poder lograrlo. Hay que considerar que en aquellos tiempos había pocas alternativas al matrimonio, que casi era una "profesión", y la más común. La relatividad de valores que sugería la Antropología me fascinó. Fue, en cierta manera, una especie de reto personal.

En las Navidades de 1968 recorrí la provincia de Lérida buscando una comunidad que reuniera las condiciones que yo pensaba debía tener mi lugar de estudio. Creo que estas condiciones son significativas de una etapa de la Antropología española, por lo que voy a referirme a ellas. En primer lugar volvía a la provincia donde había nacido, aunque mis contactos con esa región se habían cortado desde hacía muchos años. Esta vuelta, justificada en mi caso en parte por la posibilidad, que luego resultó nula, de alguna financiación, es frecuente en otros casos y deberíamos analizar por qué se asocia tan machaconamente en nuestro país al antropólogo -experto en la diversidad cultural- con su propia región de origen e incluso con su localidad natal (5). Buscaba además una comunidad bastante alejada, recoleta y exótica; las poblaciones de las Garriges me parecieron demasiado grandes y modernas por lo que me dirigí hacia los pueblos altos del Pirineo. Recuerdo que llegué a Isil, el último pueblo antes de la frontera con Francia -ya no había nada más allá- pero no me gustó nada su incipiente turismo y las esporádicas visitas de montañeros.

Evidentemente, buscaba al buen salvaje incontaminado. Y no lo encontré en Lérida sino que creí encontrarlo en Asturias, donde repetí viaje exploratorio justo un año después, en diciembre de 1969. Los vaqueiros de alzada, pueblo exótico por excelencia, marginal y marginado e incluso sospechoso de tener un origen infamante, fue justo lo que necesitaba. No tenían coches, retretes, televisores e incluso algunos ni agua y ni siquiera luz eléctrica. Al poco de llegar empezaron a contarme creencias y prácticas 
extrañas, en las que yo no creía, y que empecé a llamar, en jerga profesional, "ritos" y "mitos". Sin embargo, tuve suerte: era una gente lo suficientemente lejana a mí misma como para obligarme a ver y a escuchar, enseñarme a fuerza de práctica mucha de la Antropología a la que entonces no podía acceder por falta de institucionalización de la disciplina.

Mientras escribía estas líneas contemplaba en mi biblioteca un pequeño estante con mi colección de Antropología de aquellos tiempos que recogía a lo sumo -y con mucha elasticidad en cuanto a su filiación se refiere- una docena de títulos que todavía conservo amorosa y cuidadosamente forrados de papel azul. Ahí aparecen, además de algunas monografías sobre España -prácticamente todas en inglés que intentaba leer con mucho esfuerzo-, el libro que sin duda me produjo mayor impacto, como a otras muchas mujeres de mi tiempo: Sexo y temperamento de Margareth Mead. Su trabajo es hoy muy justamente criticado y cuestionado, pero es indudable la originalidad de su planteamiento y el impacto y relevancia que ha tenido su obra. A través de los Mundugumor o los Arapesh algunas españolas del 68, como yo misma, nos percatamos de la relatividad de las clasificaciones sexuales y cómo la definición de la mujer era algo cultural, y no natural como se nos intentaba convencer desde la Familia, el Municipio y el Sindicato.

Lo pude comprobar en mi propio trabajo sobre los vaqueiros. Ellos y ellas me enseñaron en carne propia que ser mujer podía ser incluso bastante diferente a lo que la clase media ciudadana opinaba al respecto; afortunadamente para mí, los vaqueiros me ofrecieron el contraste que necesitaba en mi éducation sentimentale. Voy a poner un ejemplo. En uno de los pueblecitos en que trabajé, una de las mozas tuvo un hijo de soltera. Al cabo de unos días al pasar por delante de su casa para ir a otra, me quedé charlando con el padre de la chica pero sin decir una palabra sobre su nieto; le noté poco charlatán y pensé: "la vergüenza". A la vuelta sin embargo me armé de valor y le pregunté por ambos. El suspiró aliviado, me introdujo en la casa y alborozado me enseñó su nieto, al tiempo que me reñía por no haber preguntado antes por él y por la madre: "Creí que estabas enfadada con nosotros" -dijo-. La "vergüenza" evidentemente estaba en mis ojos; la Familia, el Municipio y el Sindicato habían hecho su labor, y la imagen de la universitaria pretendidamente "liberada" que pensaba era no quedó muy bien parada. A través de este incidente además conocí algunas de las expresiones que se referían a un hijo de soltera: éste era un hijo "de por el mundo" (el mundo equivale aquí a lo desconocido) "de por Dios" (Dios es algo así como la casualidad) y de "por amistad" (en oposición al matrimonio). No me negarán que estas expresiones encierran ( $y$ especialmente la última), además de mucha gracia y encanto, toda una lección. El trabajo de campo, tal como lo considero, enseña bastante más de lo que pensamos y probablemente mucho más sobre un material que no tomamos en cuenta: nosotros mismos. Algo de esto indica también Barley al afirmar que "Como la vida monástica, la investigación erudita no persigue sino la perfección de la propia alma“.

¿Cuáles eran mis hipótesis, planteamientos, estrategias y líneas de investigación? Pues prácticamente ninguna: un magnetofón al hombro, ganas de ver y escuchar y mucho entusiasmo. En pocas palabras, era una devota del Dogma de la Inmaculada Percepción, practicante del más puro empirismo malinowskiano, algo más que ingenuo. En vez del consabido cuaderno y lápiz que Murdock recomendó a su angustiado estudiante ante su próximo trabajo de campo, yo llevaba, -maravillas de la técnica y el progreso- un magnetofón al hombro -un voluminoso magnetofón en aquel tiempo-. Se suponía que iba a realizar un estudio de comunidad, pero en aquel momento yo ni sabía que lo que estaba haciendo se llamaba así. Antes de ir a Asturias había pasado meses en el Museo del Pueblo Español leyendo todo lo posible sobre folclore e historia de la zona, pero mi mayor influencia provino de las clases, lecturas y enseñanzas de mi director de tesis, de quien adquirí una idea básica y muy primaria sobre qué era la cultura y cómo estudiarla.

Mi tesis doctoral (6) versó sobre la base ecológica y social del grupo vaqueiro y las razones de su marginación. Muy pronto me di cuenta, por ejemplo, que la vaca interfería de un modo insospechado en muy variados y diferentes contextos de la cultura en cuestión, por lo que intenté "seguir la vaca" -el animal como cultura, no como natura-. No me voy a referir extensamente a las circunstancias de esta investigación puesto que ya lo he hecho en diversas publicaciones (7). Pero sí quiero destacar que mi entusiasmo por la disciplina, el interés por este grupo -y quizá un cierto "olfato" etnográfico- suplió mi 
escasa preparación. Pese a mi falta de planteamiento, cuarenta años después, creo que, aún sin ser muy consciente de lo que hacía, fui capaz de recoger un rico material, posiblemente bastante original, que he podido más tarde elaborar y analizar en profundidad. En esta recogida fue básico en mi trabajo el empleo del magnetofón, un instrumento que me ayudó en gran medida -a pesar del enorme esfuerzo de transcripción- a escuchar lo que de otro modo inconscientemente hubiera perdido, despreciado $u$ olvidado. Esta técnica de recogida de material, me ha servido también posteriormente como medio de presentar la evidencia etnográfica de modo que preserve la espontaneidad y frescura local y también me ayude a trasmitir lo más valioso y rico de la experiencia de campo que suele quedar fuera de las monografías en muchas ocasiones. Parece, como han indicado Marcus y Fischer (8) que estas primeras etnografías, pese a sus deficiencias, son productos más vivos e imaginativos -supongo por la pasión puesta en ellos- que las publicaciones posteriores a la tesis, más académicas y menos sorprendentes. Había permanecido en el área 11 meses en total, a tiempo completo. La práctica de la etnografía, esa experiencia tanto humana como intelectual, me hizo madurar en ambos sentidos. De aquí parte mi interés por la etnografía y la relevancia que personalmente concedo al proceso etnográfico en Antropología.

Mi siguiente trabajo fue realizado de una manera muy diferente. Me había sido concedida una beca para estudiar en la Universidad de Pennsylvania a donde me dirigí en agosto de 1972. En aquel momento no sabía apenas nada de esta Universidad ni de la ciudad en que estaba situada; como se sabe, hay una gran variación y diferencia entre las universidades americanas privadas y públicas y aún entre estas últimas. Afortunadamente, cuando me consolaba pensando que al menos iba a asistir a muchos conciertos de la Philadelphia Orquestra, la Universidad resultó ser una de las mejores. Los comienzos fueron difíciles en muchos sentidos, adaptándome a un sistema de estudio y unas materias nuevas y desconocidas para mí, a una cultura y un lenguaje diferentes, pero al mismo tiempo también fue una valiosa experiencia. Ya he comentado en otra ocasión (9) que mi choque cultural por excelencia lo viví entre los americanos. Permanecí tres años en esta Universidad cursando el Doctorado en Antropología (10).

Mi investigación previa entre los vaqueiros había sido clave en mis estudios posteriores puesto que a la base teórica, que fui gradualmente adquiriendo, unía la experiencia de campo con la que intentaba relacionar lo aprendido. Y lo ha sido después; aunque no había pensado volver a trabajar entre los vaqueiros, a la hora de planificar mi segunda tesis doctoral consideré con mis tutores Goodenough y Reina la posibilidad de volver a realizar nuevo trabajo de campo en el mismo grupo puesto que tal como había planteado el proyecto -y esta vez, a diferencia del anterior, estaba realmente pensado y planeadoy dada la naturaleza del tema elegido, la muerte, tan íntimo y delicado en algunos aspectos, podría ser difícil de estudiar entre gentes que no conociera bien. Además, el proyecto tenía la suficiente envergadura y complejidad como para no tener que cubrir los necesarios prolegómenos de un trabajo de campo entre nuevas gentes. Así y todo volví tres meses a Asturias a finales de 1974 para sopesar la viabilidad del proyecto y recoger material sobre el tema. En mi propuesta de investigación planteo conscientemente, con un rigor ausente en la anterior etapa, la perspectiva teórica y metodológica con que me enfrento al tema de la muerte entre los vaqueiros.

El tema de esta tesis no era producto del azar sino una consecuencia de mi trayectoria intelectual y humana. Por una parte partía de un antecedente de mi propia experiencia de campo tras el suicidio de un vaqueiro en la localidad en que me encontraba, que pude estudiar en profundidad. Esta forma de morir, me percaté, no era un suceso aislado o extraño sino mas bien algo frecuente y familiar. Cuando inicié mis lecturas sobre la muerte comprobé lo escasamente estudiado que había sido este rito de passage en relación con otros, como el matrimonio o el nacimiento -del tabú hacia la muerte, pues, participaban también los propios antropólogos-. Además, me encontraba en una sociedad donde la gente se marchaba de otra manera y el tema era mucho más lejano. Como ha dicho en una ocasión Julián Marías "la muerte no tiene pasaporte americano" y por ello se la intenta camuflar con maquillaje, como el que se aplica a los muertos, o se la esconde detrás de paredes infranqueables en las salas terminales de los hospitales. Es muy probable que mi audiencia -el hecho de hacer una tesis americana- haya condicionado en buena medida mi elección del tema. $Y$ también ha condicionado, cómo no, mi postura humana ante el problema de la muerte y cierta osadía personal al pretender desentrañar un tema que en 
Al regresar a España, volví al campo y luego comencé a aprender a enseñar. Durante unos años reanalicé el material recogido para mi primera Tesis Doctoral, elaborada muy apresuradamente. Evidentemente, en cuatro años había madurado mi pensamiento sobre el tema, especialmente después de los 7 meses de trabajo de campo adicionales pasados entre la misma gente. Por ello, elaboré este material con cierto mimo y quizá algo de pudor puritano ante la publicación. Algo después inicié la redacción de mi tesis de Pennsylvania, que terminé a finales de 1983. Es difícil tener que escribir con las apretadas obligaciones docentes que tenemos los enseñantes en este país, pero esta investigación fue particularmente costosa en tiempo, dedicación y dinero. En su día, simplemente fichar el rico material que había recogido me llevó algo más de un año y el esfuerzo se multiplicó al analizar este material que había recogido y registrado con métodos casi "artesanales" (ni qué decir cabe que no gocé en esos tiempos de las ventajas del ordenador). De esos años recuerdo especialmente el trabajo que lograba sacar adelante en épocas no lectivas y los veraneos pasados en casa analizando tan "alegres" aspectos de la muerte, como la enfermedad y el suicidio. En este trabajo traté de mostrar como la muerte no es un hecho aislado y puramente biológico sino que está en estrecha relación con la enfermedad, el sufrimiento y la desgracia por una parte y con la vida, la salud y el bienestar por otra. Por ello el contraste entre la muerte natural y la muerte violenta; ambas formas de morir son los dos extremos del continuum de la muerte. De igual modo la frontera de la muerte es bastante más amplia de lo que se ha pensado; la muerte comienza en vida y va mas allá de la muerte a través de las creencias sobre los "espíritus". En otras palabras, la muerte puede ser considerada como un proceso cultural -éste es precisamente el título de mi tesis en inglés (11)-. Las fronteras, debo decir, no solamente han sido importantes en mi vida profesional sino también en mi vida personal. Las implicaciones psicoanalíticas de los temas que escogemos creo que son importantes a la hora de realizar la crítica de los contenidos y enfoques de nuestro trabajo.

Aparte de su contenido, también me preocupaba y está implícito en mi investigación el problema de la presentación de la evidencia etnográfica. Por supuesto la presentación de material recogido en magnetofón no era una innovación en sentido estricto -se había venido utilizando desde hacía muchos años- pero sí me responsabilicé de su concreta utilización en mi trabajo; mi análisis dependía en gran medida de este material. Frente a mis descripciones, preferí ceder la palabra a los propios actores pero además traté de apoyar mis interpretaciones en los comentarios populares. Probablemente este interés por la palabra local tiene bastante que ver con el grado de dominio de la lengua por lo que tiende a ser mas empleado por el antropólogo nativo que por el foráneo. Pero también creo que tiene que ver con el grado de seguridad de uno mismo y el que uno trasmite en su interacción con los demás. Hay gente aparentemente muy convencida de su percepción que se muestra muy segura en sus interpretaciones. No es éste mi caso y prefiero, si es posible, tratar de ofrecer ambos discursos, el suyo y el mío. Porque, además, creo que no se puede sustituir uno por el otro, ni merece la pena.

Mis dos investigaciones sobre los vaqueiros tuvieron sus ventajas y sus inconvenientes. La ventaja mayor de la primera fue el elemento sorpresa que lógicamente estuvo amortiguado en la segunda, puesto que ya conocía el terreno y la gente. Pese al entusiasmo juvenil de mi primera etapa, la facilidad con que la gente me proporcionaba la información y me reincorporó a sus vidas en la segunda fue evidentemente otra ventaja. Frente a la experiencia que llevé en el segundo caso, la espontaneidad y frescura de la primera investigación. ¿Quiere esto decir que uno puede ir al campo con muy poca preparación?

Pues yo creo que puede, pero que no debe, por varias razones. En mi caso tuve que hacer de la necesidad virtud, pero no hay porqué pasar necesidad, si se puede evitar. Una buena preparación teórica y metodológica no es automáticamente una garantía en trabajo de campo, pero puede ayudar a conjurar malos momentos en que una duda de poder llevar a cabo lo que se propone -si es que sabe que se propone- y cómo llevarlo a cabo. Estas dudas e inseguridades son inevitables y me temo que todos novatos y veteranos- las padecemos, pero viene bien saberlo y relativizar. Lo que si puede ser una garantía es una buena información teórica, conocer previamente que las genialidades que a una se le ocurren ya fueron planteadas o rechazadas hace años. Incluso la preparación puede servir -junto con 
algo de sentido crítico y libertario- para volver a plantear con nueva luz lo que dogmáticamente se puede haber rechazado sin mucho fundamento (12) y también para evitar la consideración canónica de ciertos textos clásicos. Pero quizá, lo más importante es que no deberíamos abusar de nuestros sujetos de estudio, los informantes, quienes deben sufrir con infinita paciencia al inexperto y sus interpretaciones. Si reparamos en ello, el trabajo de campo es ciertamente una actividad egoísta puesto que decidimos unilateralmente utilizar a un grupo de individuos como fuente de información, mientras ellos no eligen ser estudiados.

En resumen, mi trabajo de los vaqueiros, en conjunto, creo que bien puede muy considerarse dentro de una trayectoria histórica no excesivamente alejada de la de otros colegas. En primer lugar un estudio de comunidad -y una comunidad bien exótica y marginada- que empezaba de un modo clásico con la ecología, modos de vida, sociedad y cultura. Más tarde el estudio de un problema, la muerte, que aunque referido a una gente concreta, me permitió trascender la localidad. ¿Y después qué? Al acabar este último trabajo y tener que pensar que significaban mis datos sentí necesidad de volver la mirada a otro lado. Pese a que hubo gente que me sugirió seguir especializándome en pastores, grupos marginados o en el tema de la muerte, en aquel momento decidí cambiar radicalmente de tema, gente y problema. Aunque había estudiado aspectos bien dispares entre los vaqueiros, dos tesis ya era bastante; me encontraba en cierto modo saturada de trabajar tantos años con la misma gente e inquietantemente identificada por mis colegas con este colectivo (13). Creo que este es un sentimiento compartido también por muchos de ellos que pasan años en el mismo grupo. Pero además pretendía conscientemente un cambio radical porque el riesgo de la especialización excesiva es el considerar al ser humano tras una única experiencia -en mi caso ver el mundo a través de una perspectiva ganadera-.

La Antropología es la propia historia de sus autores: si en los años setenta buscábamos al buen salvaje incontaminado, rural y exótico, en los 80 buscábamos al ciudadano común, envuelto en gasolina y con la inocencia perdida -porque ese "salvaje" ya había emigrado a la ciudad hacía años-. Frente al hábitat disperso de mi anterior investigación, sentía la necesidad de descubrir cómo vive la gente en la ciudad, un buen grupo de gente junta. Me interesaba, además, la historia y la relación de la comunidad con su contexto mayor y estaba decidida a estudiar el simbolismo y emplear la metodología cualitativa en un contexto aparentemente tan poco adecuado como es la ciudad. Por último había que considerar la escasez de estudios de la ciudad en antropología. Antes de elegir una ciudad, empecé a trabajar sistemáticamente la bibliografía sobre el tema a través de lecturas y cursos que impartí. Tras sopesar varias alternativas había decidido estudiar Ávila por un conjunto de razones. No solo razones de tipo intelectual y teórico (la naturaleza de la problemática urbana a investigar) cuanto por razones de tipo táctico y práctico (su adecuado tamaño para ser estudiada de un modo global y sistemático como pretendía, o su cercanía de Madrid) de relevancia en el conjunto español (por la muy poca investigación llevada a cabo en Castilla) o por sus características específicas como ciudad -me intrigaban especialmente sus formidables murallas medievales- (14).

La vuelta al trabajo de campo en un contexto tan diferente fue difícil. Depende de muchos factores, pero creo que entre los más definitivos está la naturaleza de la sociedad que se analiza y las características del investigador. Voy a referirme a algunas de ellas desde mi perspectiva e intentar relacionar esta experiencia con la anterior. Una diferencia clara es evidentemente el tipo de acercamiento y role que uno tiende a ocupar en distintas sociedades. En mi anterior investigación mi edad me permitía con facilidad ocupar el role de estudiante tan adecuado a la tarea etnográfica; además, era estudiante y coincidía mi aprendizaje de la cultura y mi aprendizaje profesional. Mi origen de afuera de la zona y la propia conciencia de aislamiento por parte de los vaqueiros, permitía la formulación de las más variadas y básicas preguntas. En general, se me consideraba con cierta misericordia por arrostrar las supuestas incomodidades de la vida en las brañas y la gente me animaba aludiendo a que "me iban a contar todo para que sacara buenas notas en mis estudios". Es bien cierto que alguna vez también me reñían por considerar que ellos mismos u otros ya habían respondido adecuadamente a mis aparentemente ingenuas y reiterativas cuestiones. También decían en tono de broma, sonriendo y moviendo la cabeza cuando les planteaba temas delicados "Esta María... ¡hace unas preguntas...!".

Pero este role es adecuado en la adecuada edad; con los años, como es mi caso, (aunque 
evidentemente depende del contexto) y siendo ya profesional, uno corre el riesgo de que se le considere más bien "simple" si intenta utilizar la ingenuidad como estrategia en trabajo de campo. Las preguntas aparentemente inocentes del etnógrafo pueden no tener la respuesta informativa que uno espera, sino que "dicen algo" sobre el propio investigador y su consideración de los informantes. En algunos casos o bien se sospecha que el etnógrafo está tomando el pelo a los informantes o bien que es un poco tonto y en ambos casos la situación puede llegar a ser difícil. En este sentido creo que el antropólogo extranjero ocupa una mejor situación en su role de "aprendiz" porque en este caso el informante hace siempre algún tipo de esfuerzo por traducir y presentar su cultura -algo que se da por hecho que el de casa ya conoce y al que por tanto no se explicita-. Además, creo que precisamente el hecho de ser enseñante provoca en la gente la peligrosa suposición de que una conoce más de lo que realmente conoce (por definición, la "maestra" tiene que saber).

Y también depende de qué se estudia. Del antropólogo nacional en la zona rural se esperaba la petición de información que el informante consideraba característica de la profesión, material generalmente bastante intrascendente (folclore, costumbres y prácticas "antiguas" o lo curioso y extraño de la comunidad) (15), pero si el antropólogo se salía de esta adscrita información al menos tenía que explicar porqué. Otro caso es el del antropólogo foráneo que, por ser extranjero, en cierto modo "extraño" y poco predictible, se le tolera la formulación de cuestiones más sorprendentes o atípicas. Pero incluso éstas son más fáciles de explicar en la ciudad, más acostumbrada a la diversidad de especializaciones que en la zona rural y también más acostumbrada a la investigación y al saber académico. Aquí radica una fuente a la vez de fricción y colaboración con los "nativos" de la ciudad. Mientras que en la zona rural la competencia con los informantes es nula -y por ello a mi me dedicaban bromas sobre que "debería comprarme una vaquina"- en la ciudad esta posibilidad es real porque existen diversos tipos de investigadores y pueden manifestar cierto recelo ante el "intruso", aunque lo más frecuente es, o debería ser, la mutua colaboración e intercambio (16). Quizá esta última situación urbana encierra una mayor igualdad y realismo frente al más distanciado contexto rural sobre el que se aplica un halo romántico que probable y secretamente contenga visos de complaciente superioridad. En cualquier caso, el etnógrafo debe enfrentarse con la identidad que se le adscribe y con las inferencias que los demás hacen de sus intenciones. Las relaciones humanas en el campo cambian, se desarrollan continuamente, por lo que también continuamente debe clarificar su identidad. Sin embargo, a pesar de que suspicacias de varios tipos hubo en ambos lugares, es bastante peor la situación en la ciudad ya que en la pequeña comunidad la gente termina por acostumbrarse a una y en la ciudad una no termina de conocer a la gente -la suspicacia puede permanecer durante todo el trabajo de campo-. Así, en Ávila continuamente tuve que presentarme una y otra vez e indicar lo que hacía, a pesar de que mis mejores amigos aseguraban, sin mucha base, que conocía "a media Avila". Eso sí, los errores del etnógrafo también se diluyen mejor en el anonimato ciudadano.

También cambió el tipo de reciprocidad con que traté de poner de manifiesto mi gratitud al grupo que estudiaba. En el caso de Asturias, fui durante tres semanas maestra y después llegué a ser por una temporada la taxista del entorno -especialmente solicitada en emergencias -frecuentemente partos humanos y animales-. En la ciudad mis actividades han sido muy diversas y recuerdo esporádicamente haber cantado de contralto en una iglesia, vendido libros en una feria, ayudado en la organización de unas jornadas o acompañado solidariamente a una opositora, pero en general se me ha solicitado impartir algunas clases o conferencias de Antropología. Esto es algo que hago normalmente y muestra que la especialización ciudadana toma en cuenta mi especialidad si la precisa, mientras que en la zona rural fueron valorados otros conocimientos y básicamente mis servicios como "chofer" (17). Mi forma de interacción también varió considerablemente. La vivienda por ejemplo; en Asturias vivía con la gente en sus casas en estrecha relación y este contacto fue muy básico para entender la cultura vaqueira puesto que la forma de vida, economía, relación social, etc., de cada casa, aun con sus diferencias, era muy similar. Por otro lado, me hubiera sido difícil encontrar acomodo en algunos lugares si en vez de ir sola hubiera ido, por ejemplo, con familia; no fue infrecuente compartir mi cama con una joven de la casa. En cambio si hubiera elegido, que no fue el caso, vivir con una familia en Ávila, estoy convencida que hubiera podido vivir una clase de vida y probablemente ello me hubiera supuesto ignorar otras o al menos reducir mi libertad de movimientos. La ciudad, por definición, es la organización de la diversidad y puesto que mi interés se centra en esa diversidad, la intensidad en un segmento se ganaría a costa de 
los demás. A mi relación más estrecha y afectuosa entre los vaqueiros se opuso la mas impersonal relación ciudadana, si bien he tratado ( $\mathrm{y}$ espero haber conseguido) de hacer amigos en ambos lados. La etnografía, tal como la considero, no es solo un encuentro científico sino también un encuentro intensamente humano. Pero si bien el contacto es inmediato en el primer caso y uno conoce bastante bien a los habitantes de pequeñas comunidades, el segundo es más lejano y está mediatizado por el teléfono, un instrumento básico para el contacto en una ciudad, aunque sea pequeña como Ávila, de algo más de 40.000 habitantes cuando comencé a estudiarla. El delicado problema de encontrar, cultivar y cambiar informantes es más difícil en la ciudad, más anónima, donde la gente se puede defender mejor del aguerrido investigador, dicho sea de paso.

Otra cosa que interfirió en mi trabajo en la ciudad fueron mis obligaciones laborales. En enero de 1987 iniciaba mi trabajo de campo a tiempo parcial -media semana la pasaba en Madrid dando mis clases y media en Ávila- y así continué hasta mayo. Me dí cuenta que los sucesos más interesantes de la ciudad sucedían cuando yo no estaba y que esta especie de esquizofrenia que me traía entre Ávila y Madrid repercutía tanto en mis clases como en mi investigación. Mi conocimiento de la ciudad en esta situación era un tanto discontinuo y parcial. Llevaba doce años dando clase ininterrumpidamente por lo que me decidí a solicitar en mi Departamento se me liberara de mis obligaciones docentes durante un curso académico (18). Así desde mayo de 1987 a junio de 1988, viví con intensidad la vida de la ciudad. La diferencia entre este periodo y el anterior es tan significativa que merece una reflexión. A la institucionalización de la disciplina en este país, no ha seguido la institucionalización programada de la actividad investigadora. Personalmente estimo que la tesis doctoral no debe ser ni la última ni la única investigación realizada con intensidad y con un trabajo de campo prolongado y continuo. Los estudios de fin de semana en el mejor de los casos y/o de un mes de vacaciones, por ejemplo en investigaciones de ultramar, no creo que se puedan considerar (y con cierta generosidad) más que viajes exploratorios a lo sumo y no, como a veces se pretende, investigaciones completas. Creo que es muy adecuado que el profesor dirija investigaciones pero, además, que las pueda realizar él mismo.

Después de un año de permanencia había logrado la experiencia de la ciudad de un modo global y sistemático. Pero el estudio de una ciudad por su complejidad y heterogeneidad no se puede llevar a cabo en tal periodo, como si fuera una sociedad a pequeña escala. Se me plantearon, entre otros, problemas de acceso, limitación de la observación participante, representatividad, relevancia macroscópica, replicabilidad y verificabilidad. El año pasado en Ávila me permitió un conocimiento básico de la ciudad, entender a grandes rasgos su estructura física, social y mental: sus áreas y barrios, grupos sociales y colectivos significativos, creencias, rituales y otros aspectos ideológicos claves para empezar a captar la visión del mundo abulense. Esta etapa fue imprescindible para la identificación y conocimiento de la problemática urbana. Ahora bien, la recogida de material de un modo sistemático, y no solo de una manera tentativa, ha sido posterior y todavía la estoy realizando. Y esta recogida de material incluye bastante más que los datos que el antropólogo elabora normalmente, aunque éstos sigan siendo esenciales según mi opinión, y supone una mayor complejidad de información; por ejemplo, el hábito que adquirí en su momento de leer todos los días el periódico local (que irónica y cariñosamente los propios abulenses denominaban "la hoja parroquial").

Muy significativamente el cambio de tema y lugar de estudio, mi investigación sobre la ciudad, me supuso una preocupación mayor por nuestras maneras de percibir y pensar, un replanteamiento de las formas de plasmar la evidencia etnográfica al mismo tiempo que realizaba una reflexión seria sobre la teoría y metodología antropológica. El antecedente más antiguo es probablemente mi investigación de la muerte donde planteo en el último capítulo la necesidad de comparación con otros sistemas culturales y profundizar históricamente en visiones del mundo en otros lugares. Hasta aproximadamente el año 1985 mis publicaciones están fundamentalmente basadas en mis datos de campo a pesar de que en su análisis empleo un fundamento teórico cuidadoso. Sin embargo, a partir de esa fecha, comienzo a publicar, si bien tímidamente, sobre aspectos teóricos y metodológicos de la disciplina y especialmente sobre la naturaleza del proceso y el producto etnográfico (19). Las etnografías normalmente presentan los datos, pero se dice muy poco sobre la manera en que han sido recogidos y creo que una información clara y directa sobre las circunstancias y premisas del trabajo de campo proporciona una mayor posibilidad de comprensión de los datos y evaluación del trabajo. Dentro de estas preocupaciones inicié 
también una reflexión sobre la Antropología que se ha venido realizando en este país tanto por parte de los antropólogos extranjeros como por los propios españoles.

El cambio de lugar me hizo también reflexionar sobre cuestiones de epistemología básica de la disciplina. Cuando empecé a revisar la bibliografía sobre el tema de la Antropología Urbana comprobé lo nuevo del campo y la poca sofisticación del estudio realizado en la ciudad. Normalmente se había estudiado este medio ambiente como un lugar hostil y difícil, lleno de grupos pobres, culturalmente diferentes y sin historia. Se había enfocado poco como comunidad urbana y aún menos como se encuadraba la ciudad, en términos de interacción e ideología, en la sociedad más amplia. Ni que decir que apenas había trabajos sobre simbolismo en la ciudad y especialmente pobres eran los criterios de comparabilidad (20).

Siguiendo los lemas de Ávila ("la ciudad de los santos" y "la ciudad de las murallas") traté de estudiar la mitología de una ciudad (21) hecha para la guerra y la mística, en varios sentidos "elevada", fundamentalmente de frontera. El trabajo de campo de Ávila me mostró que para entender la ciudad de hoy día es imprescindible el estudio de lo que significa el tiempo y el espacio. Los abulenses dotan a los viejos espacios con nuevas significaciones, pero se mueven a través de escenarios heredados. La exploración de la naturaleza de estos símbolos ha sido muy fructífera y una buena guía para el análisis de la ciudad de hoy día ya que se corresponden con los niveles significativos de la misma: ecológico (las murallas), social (los caballeros), ideológico (los santos).

Mi siguiente investigación fue una continuación de ésta pero en un contexto diferente. En un Seminario de la UIMP que organicé en Santander en agosto de 1989 y que se llamaba Los españoles vistos por los antropólogos, (22) se plantearon una serie de cuestiones históricas, estructurales y epistemológicas de la disciplina y además incidió en los problemas derivados de la procedencia, personalidad y preparación del antropólogo. Mi ponencia, que llevaba por título "Desde una fresca distancia. ¿Por qué no estudiamos a los norteamericanos?" era una clara defensa de la perspectiva transcultural que se debería practicar algo más en la Antropología española que, según mi parecer, era, en aquellos momentos, casera y parroquial. En este trabajo abogaba por la investigación en Portugal, Marruecos, Europa y América. Frente al numeroso colectivo norteamericano de antropólogos asistentes al Seminario, utilizaba como metáfora la pregunta ¿por qué no estudiamos a los norteamericanos? para analizar los sesgos y carencias de la antropología española del momento.

Con este antecedente tenía muy claro que iba a trabajar fuera de España en mi siguiente trabajo de campo. Estuve sopesando varias posibilidades en Estados Unidos (visité Richmond en Virginia, Charleston en Carolina del Sur o San Agustín en Florida) pero me decidí finalmente por Portugal, un país cercano que visitaba y apreciaba desde hacía años. Así elegí Évora por su parecido con Ávila; ambas ciudades eran Patrimonio de la Humanidad, interiores, en su origen ciudades de frontera, amuralladas, de tamaño similar, y con un protagonismo histórico cada una en su contexto. A Ávila se la conocía como "la ciudad de los santos" y a Évora "la ciudad de las iglesias". Había interesantes coincidencias entre ambas (el fuero de Ávila se conoce por el de Évora y comparten ambas los mismos santos mártires) si bien también hay significativas diferencias (por ejemplo una muy diferente ideología política en sus respectivos Ayuntamientos (23). Ciudades que a pesar de su mismo tamaño tienen muy distinto peso en el conjunto regional y nacional (Ávila es una pequeña ciudad castellana y Évora la capital del Alentejo).

A diferencia de Ávila, lo primero que estudié en Évora es su mitología, un buen punto de partida porque señala momentos álgidos de la ciudad, las preocupaciones más relevantes en diferentes épocas y como se presenta al exterior. Las viejas corografías, la ostentación de sus emblemas y mitologías tienen trascendencia en las piedras y memorias de la ciudad y en las vidas de sus gentes. Las representaciones de la ciudad y su carácter simbólico me ocupan en la actualidad. Desde que pensé trabajar en Portugal uno de mis mayores preocupaciones fue la interrelación con mis colegas portugueses; al igual que se dice de ambos países que "han vivido de espaldas" a pesar de su cercanía, nuestro conocimiento mutuo era bastante escaso y discontinuo. Una serie de pequeñas reuniones periódicas bianuales en España y Portugal que inicié en su día han intentado paliar en parte este desconocimiento y representan para mi una de las mejores y más enriquecedoras experiencias de amistad y colaboración (24) con mis colegas 
portugueses. El trabajo de campo entre los vecinos ofrece interesantes perspectivas: es la mirada de iguales, desde una tradición cultural similar y a la vez diferente que permite cierta sofisticación del "de dentro" y al mismo tiempo una "saludable distancia" (25). Parte de la tradición cultural ibérica es la valoración de la profundidad histórica de ambas culturas, por ejemplo en las ciudades y ello puede suponer nuevos planteamientos; ya sabemos que la mirada antropológica es cultural y el resultado depende mucho del que mira y de qué y cómo miramos.

No todos los investigadores están de acuerdo en la metodología de la investigación comparativa, pero si comparten la idea de que la comparación es una parte importante de la Antropología y que todas las teorías requieren que se prueben. Sencillamente para entender porqué una cultura es como es se debe comparar con otras. Siempre hay una comparación implícita cuando estudiamos a otras gentes, pero debería ser consciente, explícita y sistemática. En mi caso la comparación ha sido clave no sólo para entender Évora sino también para entender Ávila. Fueron precisamente contrastes y similitudes los que me permitieron percatarme de diferentes aspectos que había dado por hecho en mi propia cultura. El tener que aprender un idioma, una cultura, me obligó a repensar mis datos abulenses, a entender mejor ambas ciudades y a reflexionar sobre la imagen de mi misma y de mi propio país (26).

Para terminar quisiera indicar un par de ideas. Primero que, a pesar de las diferentes investigaciones, mis andanzas y mudanzas, creo vislumbrar en mi trayectoria profesional una línea de trabajo, no siempre consciente, mantenida a través de diferentes contextos. Podría quizá definirse como una preocupación y casi fascinación por la ambigüedad y el límite. Los vaqueiros, como otros marginados españoles, habitan por definición el límite de la sociedad española como bien ha indicado Susan Tax en el último capítulo de su libro sobre los Pasiegos (27). Para límite también, la muerte, esta vez límite temático por excelencia entre diferentes mundos (que es precisamente como he denominado mi investigación en castellano). Ávila y Évora se pueden considerar límite por su tamaño (entre lo rural y lo urbano) su historia (su creación entre culturas) su elevación y su visión del mundo; por algo una es una ciudad "de santos" y la otra una ciudad "de iglesias". Mi interés por el límite y la ambigüedad se debe no solo a que encapsulan y contrastan con dramática lucidez la propiedades opuestas de sistemas contrapuestos, sino porque además la ambigüedad puede ser un instrumento de interpretación y de explicación en mi trabajo. Y creo también que representa de un modo más real la naturaleza de nuestro cometido. Las distinciones claras y nítidas están frecuentemente en la cabeza, o en los deseos, de los investigadores más que en el material rico, diverso, ambiguo y lleno de matices que analizamos.

En segundo lugar, es probable que se pueda pensar que mi trabajo ha sido elaborado muy lentamente. Si alguien lo piensa, tiene razón. La investigación antropológica es muy costosa en tiempo, esfuerzo y dinero. Dada su larga duración, su carácter cualitativo y la profundidad de análisis, frente a otras disciplinas, no siempre es un trabajo entendido ni, por ejemplo, de fácil adaptación a los plazos y requisitos usuales de las convocatorias de ayudas. La pretensión de realizar un trabajo antropológico en tres o seis meses pongamos por caso, que puede ser un plazo razonable para otras investigaciones puede ser, según mi parecer, muy precipitado en el caso de nuestra disciplina. Creo que algunas de estas no infrecuentes ofertas, pese a sus (en ocasiones) sustanciosos beneficios tanto económicos como coyunturales, deberían o bien considerarse como un pre-estudio, un mero reconocimiento sobre el terreno que debería o bien replantearse en plazos antropológicamente significativos, o rechazarse porque a la larga se vuelven un arma contra su autor y la disciplina. Un antropólogo realiza un número bastante limitado de trabajos de campo a lo largo de su vida y especialmente si es enseñante -cuatro o cinco a lo sumo (siendo muy prolífico) y frecuentemente un par de ellos-. Esto lo ha indicado un buen etnógrafo como Evans-Pritchard (28).

Y por último, hace veinte años me preguntaba porqué no habíamos trabajado más en la ciudad. Que significaba la remora en enfrentarse a esta forma de vida tan relevante en la actualidad. Ese énfasis en campesinos que llevaban decenios haciendo el recorrido del campo a la ciudad ¿pero a qué ciudad?, ¿cómo era esa ciudad? De ello sabíamos muy poco. Y en cierta manera era extraño y posiblemente significativo; tenía que ver con los usos y características de la disciplina que le atribuía la sociedad que la practicaba. Los antropólogos ya maduros nos enganchamos en la búsqueda de las "raíces", la "esencia" de los pueblos y la justificación del nacionalismo. Tuvimos una época en que sólo trabajábamos en 
nuestra comunidad e incluso en nuestro pueblo. Aparentemente parecía que nos estudiamos, pero no era así; en realidad estudiamos a los otros, no a nosotros -aunque esos otros fueran los campesinos, los pobres o los exóticos de nuestra sociedad-. O que me digan donde hubo un sin duda fascinante proyecto de estudio de un Departamento universitario, sin ir mas lejos. Simplemente por el hecho de nuestra elección de la comunidad o grupo a estudiar, se detectaba frecuentemente una gran dosis de superioridad velada por un relativismo franciscano en la imagen bucólica de la arcadia feliz, ese paraíso perdido que todos buscamos y terminamos encontrando en el campo -o por el contrario el grupo sórdido, pobre y marginado entre los marginados al que pretendíamos redimir con nuestro trabajo-. Qué casualidad que ambos fueran los colectivos más fácilmente estudiables (y no, por ejemplo, los ocupadísimos ejecutivos). La elección de tema también delataba este tipo de complaciente superioridad esas creencias ajenas en las que no creíamos ya- y que incluso alguna vez llamamos alegremente "paganismo" o "superstición". Y el énfasis en lo bizarro, lo raro y lo nostálgico que nuestro público captaba y traducía por "espécimen" o "atrasado"; no me extraña que en muchos lugares encontráramos cierta resistencia a ser estudiados.

He empezado este artículo hablando de las andanzas de una antropóloga y ensayo ahora una reflexión de las imágenes (29) que tenía nuestro trabajo en nuestra sociedad. Este paso del individuo a la sociedad es uno de los más intrigantes que tiene la reflexión etnográfica -y de los más necesitados de análisis-. Es evidente que mi trayectoria personal puede no tener mucho sentido -y desde luego ningún interés, excepto como mero anecdotario- sino se considera como una reflexión, un intento de introspección de una manera por personal no menos cultural de adquirir conocimiento. No he pretendido hacer un relato confesional ni relatar errores, que los hay, sino solo reflexionar sobre algunos aspectos de la práctica etnográfica empezando por mi experiencia misma, por los motivos y sentimientos que me llevaron al campo y que pueden no diferir excesivamente de otros, (30) aunque estas reflexiones no abundan precisamente entre los antropólogos nacionales. Hasta cierto punto es comprensible porque todo desvelamiento encierra un riesgo de vulnerabilidad. Pero merece la pena. Me gustaría que estas líneas sirvieran para animar a mis veteranos colegas a que expongan también ellos sus planteamientos y así empezar a comprender cómo comprendemos. Y que también sirva a los más jóvenes para empezar a desmontar la mística que frecuentemente rodea al trabajo de campo.

\section{- II -}

"Tolerance of ambiguity is as much a mark of scientific maturity as of emotional maturity. Methodological uncertainty is not necesssarily a symptom of scientific malaise. It may reflect instead an embarrassment of riches in research possibilities and express the pain inseparable from growth. The modern Faust need not fear eternal damnation if he does not aspire to eternal salvation. It is enough if he can find something to draw him ever onward" (A. Kaplan) (31).

En estas líneas he tratado de convertir a uno mismo en objeto de estudio, intentar objetivar al sujeto que conoce, evocar las condiciones prácticas de la elaboración del conocimiento. En trabajo de campo es incluso probable que los mayores problemas provengan del desconocimiento de la cultura del antropólogo y no tanto de la del informante como se ha pensado comúnmente. Por citar algunos de ellos, la situación del choque cultural, la incomprensión por no conocer suficientemente de dónde venimos (y no solo a donde vamos) y el etnocentrismo, tan internalizado que difícilmente nos permite controlar nuestros sentimientos y evitar nuestros juicios. Hasta cierto punto este etnocentrismo es inevitable pero mejor reconocerlo que negarlo, y ser conscientes de las limitaciones culturales. Todo ello nos plantea la necesidad de conocer mejor nuestra propia cultura y, por supuesto, a nosotros mismos. 
campo de la teoría antropológica; pero además la experiencia misma puede llegar a ser un ensayo de Antropología, una investigación sobre nuestros modos de percibir y comprender nuestro mundo y el de los demás. Como ha indicado Rabinow, toda actividad cultural es experiencial, el trabajo de campo es una actividad cultural y esta actividad define la disciplina. No solo el antropólogo está históricamente situado a través de las preguntas que hace y la manera en que busca comprender e interpretar el mundo. También nuestros informantes nos proporcionan interpretaciones mediatizadas por la historia y la cultura, por la reflexión que en ellos inducimos, por la imagen que tienen de nosotros y la que pretenden ellos mismos tener y trasmitir. "No hay primitivos inconscientes viviendo a través de reglas rígidas en total armonía con su medio ambiente" -dice Rabinow- "hay otros hombres viviendo otras vidas". La información depende pues de la relación interpersonal, es subjetiva (entre sujetos), parcial y débil. Es importante conocer y reflexionar sobre el estatus epistemológico del material que recibimos.

\section{Notas}

1. Originalmente este ensayo fue escrito y presentado como ponencia invitada en el $V$ Congreso de Antropología que tuvo lugar en Granada en diciembre de 1990, dentro del Simposio Trabajo de campo, que dirigía Joan Frigolé, en el que se nos pidió analizáramos nuestra propia experiencia de campo. Nunca fue publicado a pesar de que, me consta, ha circulado por algunas universidades. Para la presente publicación lo he tratado de poner al día, completando esa experiencia, especialmente en notas, pero he respetado su forma y la teoría que aparece en la parte II, que pertenece al ambiente de la época en que fue escrito. Agradezco a Gazeta de Antropología, a su director y Consejo de Redacción, su amable invitación a participar en este Aniversario de la Revista.

2. De quien es además la iconoclasta cita que encabeza estas lineas. El antropólogo inocente Anagrama, 1989. Todas las citas corresponden al capítulo 1, p. 17 y ss.

3. A través de las enseñanzas de Esteva Fabregat, justo antes de marchar a Barcelona, y Carmelo Lisón recién llegado al Departamento de Antropología Americana de la Universidad de Madrid. Entré en Antropología por casualidad, porque lo que quería realmente estudiar era Psicología, pero todavía no había sido creada como especialidad cuando tuve que elegir.

4. Todavía es objeto de cierto halo de extrañeza y exotismo. Un ejemplo es un chiste, bastante reproducido, en que un niño dice algo así como: "Cuando mi familia me pregunta que es lo qué quiero ser de mayor yo digo que bombero. ¿Para qué les voy a preocupar diciendoles que antropólogo?". También es significativo el frecuente juego de palabras (y asociación) del "antropólogo" con el "antropófago" en las bromas de mucha gente sobre la profesión.

5. Yo he intentado señalarlo en el artículo "Desde una fresca distancia: ¿Porqué no estudiamos a los norteamericanos?" del libro Los españoles vistos por los antropólogos, María Cátedra (comp.), Jucar Universidad (1991). Hay varios factores, sin duda y algunos riesgos. Me temo que, de seguir así, uno puede ocupar la vieja y amalgamada figura del folclorista-historiador-sabio local que por su trabajo en zonas rurales y pequeñas y su competencia en todos los variados aspectos culturales se convierte en una especie de "cronista oficial" o "vecino ilustre" - en estos tiempos profesor universitario, eso sí-.

6. La primera etapa de esta investigación tuvo lugar entre octubre de 1970 y junio de 1971, fecha en que presenté mi Tesis de Licenciatura tras un periodo de permanencia en el área vaqueira de 4 meses. La segunda etapa de mi trabajo duró hasta Julio de 1972, en que presenté mi Tesis Doctoral. En total, había permanecido 11 meses completos entre los vaqueiros En 1972 disfruté de una Beca de la Fundación Juan March de Estudios en España que me fue concedida tras una generosa carta de presentación de Don Julio Caro Baroja. Esta financiación me liberó de las preocupaciones económicas que había sufrido durante el año anterior cuyo trabajo de campo llevé a cabo exclusivamente por mis propios - y muy 
escasos- medios.

7. La vida y el mundo del vaqueiro de alzada. CIS-SIGLO XXI, Madrid (1989) y La muerte y otros mundos, Jucar Universidad, Madrid y Gijón (1988). El primer libro se basa en el material de esta primera etapa de campo que presenté como Tesis Doctoral en la Universidad Complutense, en 1972.

8. Anthropology as Cultural Critique. The University of Chicago Press, 1986.

9. "Desde una fresca distancia", op. cit.

10. Lo normal en mi caso, puesto que ya era doctora, hubiera sido hacer algún curso de postgrado en Pennsylvania. Sin embargo decidí "reincidir" con un segundo doctorado puesto que era consciente de lo que me quedaba por aprender y por las posibilidades de poder estudiar en una universidad tan prestigiosa como esta, en la que tuve como profesores, entre otros a Anthony Wallace, Igor Kopitoff, Dell Hymes, Ray Birdwhistell, Erving Goffman, William Davenport, y mis dos tutores, Ward Goodenough y Ruben Reina . Especialmente Goodenough fue clave en mi preparación.

11. Death as a Cultural Process. The Vaqueiros de Alzada, Spain. University Microfilm International, Ann Arbor, Michigan; publicado posteriormente en inglés en 1992 como This World, Other Worlds en Chicago University Press .

12. Aunque tampoco un magnifico proyecto es una garantía de éxito en trabajo de campo. La evolución que puede tomar este en una sociedad determinada puede precisar de un cambio de planes o un replanteamiento del mismo como sucede frecuentemente. No hay una manera única de hacer trabajo de campo y al igual que cada antropólogo tiene su estilo para contactar con otros, los seres humanos que estudiamos también lo tienen.

13. Alguno, con humor, me decía al verme: "Qué, María, ¿dónde tienes la vaca?". Cuando conocí a Claudine Fabre-Vassas su comentario sobre mi fue "¡Ah! Tu eres la de la vaca" aunque yo contesté "Y tu la del cerdo". Claudine ha realizado una excelente monografía sobre ese tema (La bête singulière. París, Gallimard, 1994).

14. Preferí, además, iniciar en solitario esta investigación mas que trabajar en equipo, como he hecho mas tarde, por dos motivos: primero porque deseaba estar segura por mi misma que tanto la investigación de una ciudad era factible como que quería estudiar esa ciudad. En segundo lugar no quería embarcar en un proyecto poco usual y poco madurado a gente mas joven y con menos experiencia sin estar convencida que lo podía llevar a cabo.

15.Y deberíamos plantearnos porqué se esperaba del antropólogo este tipo de información y hasta que punto no estábamos contribuyendo a ello con la elección de ciertos temas de estudio.

16. Probablemente desde un lado porque algunos investigadores locales consideran como "propiedad privada" cualquier tema relacionado con su localidad. Desde el otro por la, en ocasiones, poca consideración y falta de respeto del foráneo hacia sus colegas del lugar.

17. Cuando llegué a Asturias, en toda una parroquia solo existía un automóvil. A diferencia de Paul Rabinow (Reflections on Fieldwork in Morocco. University of California Press, 1977) para quien la posesión de un coche y su role como chofer fue una pesada carga y una remora en su trabajo, en mi caso me proporcionó bastantes oportunidades de ensanchar los límites de las pequeñas comunidades y asistir a médicos, visitas, entierros, fiestas y otros actos en compañía de la gente.

18. A este respecto agradezco la solidaria ayuda de mis colegas Charo Otegui y Curro Sánchez.

19. Véase por ejemplo "Etnografía, la descripción de la descripción" en La vida y el mundo..., op.cit. "Prólogo a la edición española" en Paul Rabinow, Reflexiones sobre el trabajo de campo en Marruecos Jucar (1992), "Técnicas cualitativas en antropología urbana" en II Jornadas de Antropología de Madrid. Y 
"Desde una fresca distancia..." en Los españoles vistos por los antropólogos, op. cit.

20. Como justificación se aludía a la dificultad de transformar la metodología antropológica para adaptarse a la complejidad urbana. Por ello no era raro que el antropólogo en la ciudad se convirtiera en un sociólogo cuantificador y que la ciudad industrial y occidental fuera prácticamente el modelo imperante de urbanismo. Percatándome de estos problemas me interesó la línea de investigación de la ciudad como contexto, más interesante en su planteamiento que en sus resultados. En este tipo de trabajo la ciudad se percibía en términos holísticos y se reconocía su fundamental heterogeneidad de agregados, subculturas y grupos, además de las diferencias y semejanzas entre ciudades. El contexto significaba aquí la interacción de la cultura nacional con la historia local, la cultura del territorio circundante, los desarrollos internos y las experiencias externas de cada ciudad.

21. Entre mis publicaciones sobre Ávila hay por el momento tres libros: M. Cátedra, Un santo para una ciudad, Ariel (1977); M. Cátedra y S. de Tapia, Para entender las murallas de Ávila, Ámbito (2007); M. Cátedra, Paisajes de antropología urbana, Genueve (2012). Sobre el lema "La ciudad de los caballeros" dos miembros del equipo que formé en su día realizaron sendas investigaciones: E. Cabezas, Los de siempre. Poder, familia y ciudad, CIS-Siglo XXI (2000); Ana Giménez, El grupo étnico en el medio urbano: gitanos en la ciudad, Tesis Doctoral, Universidad Complutense (1994).

22. Más tarde, en 1991 publicado con el mismo título. Asistió un conjunto bastante significativo de antropólogos tanto foraneos como nativos: Caro Baroja, Pitt-Rivers, Valdés, Tax Freeman, Luque, Frigolé, Brandes, Christian, Prat, J. L. García, James Fernandez, Moreno, Cardín, entre otros.

23. He hecho trabajo de campo en Évora en dos períodos a través de dos sabáticos: uno por 25 años de docencia y otros por cargo académico como Directora de Departamento. Entre octubre del 2000 y julio de 2002 estuve 15 meses a tiempo completo. Recientemente (octubre 2011 a marzo de 2012) he vuelto por algo más de 5 meses.

24. En la actualidad (2012) se está preparando la $7^{a}$ edición; la primera tuvo lugar en Ávila en el año 2000 y dos años después en Évora; han seguido reuniones en Pamplona, Ponte de Lima, La Seu de Urgel y Miranda. A todas ellas ha seguido una publicación que recoge las ponencias en ambos idiomas: M. Cátedra (ed.) (2001), La mirada cruzada en la península ibérica. Perspectivas desde la antropología social en España y Portugal. Madrid, Catarata; Jorge F. Branco y A. I. Afonso (ed.) (2003), Retóricas sem Frontêiras Oeiras, Celta; J. M. Uribe (ed.) (2007), En-clave ibérica: vecinos, caminos y mudanzas culturales, Pamplona UPN; M. Cunha y L. Cunha (eds.) (2007), Intersecçôes Ibéricas: Margens, passagens e Fronteiras. C. Marmol; J. Frigolé y S. Narotzky (eds.) (2011), Los lindes del patrimonio. La antropología ibérica del siglo XXI, Barcelona, Icaria; J-Y. Durand (ed.) (2012), Saber, fazer (en preparación). Dado el pequeño tamaño de estas reuniones y su ambiente (unas 30 personas de ambos países) el conocimiento mutuo es muy efectivo y placentero.

25. De la parte portuguesa también hay un cruce de miradas. Dos ejemplos recientes son A. Medeiros y P. Godinho.

26. Mi investigación en Évora ha producido por el momento (2012) una decena de artículos sobre comparación de ambas ciudades, mitología de Évora, imágenes de la ciudad, etc.

27. "The Margins of Spanish Society", The Pasiegos. Spaniards in No Man's Land. The University of Chicago Press, 1979.

28. Y sin embargo no es infrecuente observar en la actualidad la existencia de, pongamos por caso, media docena o más de supuestos trabajos de campo en algunos jóvenes e inmaduros currículums. Es probable que por trabajo de campo estas personas se refieran simplemente a "paseos" de (o por el) campo. Soy consciente de que a veces hay necesidades "alimenticias" para aceptar todo tipo de encargos, especialmente en tiempos de crisis. Y por supuesto, hay muchas formas de hacer trabajo de campo y muy diferentes temas y proyectos a investigar; depende de cómo sean diseñadas para enfocar su tratamiento y duración. Sin embargo, deberían ser claramente especificados. Pero en algún congreso 
he llegado a escuchar que se puede realizar trabajo de campo ¡de un día! Y no era una broma...

29. Cuando escribí este artículo (1991) eran esas las imágenes dominantes y por ello empleo el tiempo pasado. Hoy día (2012) esas imágenes han variado por el tipo de investigaciones que se realizan, por su internacionalización y por el trabajo mayoritariamente realizado en zonas urbanas.

30. No he sido la primera -y por ello se apreciará aquí la inevitable influencia de un sensible ensayo de Brandes Stanley Brandes, “España como 'objeto' de estudio: reflexiones sobre el destino del antropólogo norteamericano en España" en María Cátedra (coord.), Los españoles vistos por los antropólogos (op.cit.). La nula presencia del propio etnógrafo en la etnografía española llega a ser caricaturesca en algún caso en que se da un intento deliberado de ocultar datos importantes que afectan la recogida de información. Últimamente, sin embargo, hay algunos ejemplos que contradicen esta tendencia (por ejemplo, J. Prat, Los sentidos de la vida, Bellaterra 2007).

31. A. Kaplan, "Philosophy of Science in Anthropology", Annual Review of Anthropology 1984, n 13: 3138. 